\title{
Factors affecting consumers' cognition of food photos using Kansei engineering
}

\author{
Mei-Yi WU ${ }^{1 *}$ (D), Ying-Hsuan $\mathrm{CHEN}^{1}$
}

\begin{abstract}
The charm of food photos plays a decisive role in advertising because people search and buy food on the Internet more frequently than ever. Photos with appealing food design elements can immediately attract people's attention. The same food with different design features will attract different consumer groups through photos on the web. They greatly affected consumers' feel, and purchase decisions. This study uses Taiwanese mango ice as an example to explore the perceptual reasons why consumers are attracted to existing mango ice products, their attractive design features, and the relationship between the two. Miryoku engineering was used to explore the relationship between consumers and the appeal of food design revealed by photos, the Evaluation Grid Method (EGM) was used to extract the attractive factors of food design, and the Quantification Theory Type 1 (QTT1) is used to analyze the weight of each design feature that affects the charm of food. Three Kansei factors and 16 concrete design elements were obtained through EGM, and the weights of food design elements that influence the charm were found using QTT1. The results show that the obtained regression models can explain the relationship between the design elements of food photos and the perception of customers. The application have important reference value for evaluating food design elements and market segmentation of consumer groups. This research proves the feasibility of using Kansei engineering to explore the charm of food design, and has reference value for future related research.
\end{abstract}

Keywords: Kansei engineering; evaluation grid method; Quantification Theory Type I; Miryoku engineering.

Practical Application: Consumers' demand for buying food online has increased because of the impact of the new crown pneumonia epidemic. Food photos displayed online play an essential role in marketing. This study takes food photos of Taiwan mango ice as an example to prove the feasibility of using Kansei engineering to explore the charm of food design. The application has significant reference value for catering industries in discovering food design elements affecting visual charm factors of consumer groups and segmenting the market.

\section{Introduction}

Providing products with emotional value and attractiveness has long been a critical topic (Ho \& Hou, 2015). Due to the increasing popularity of the Internet, combined with services such as electronic maps and delivery platforms, people are searching and buying food on the Internet more frequently than ever. Coupled with the coronavirus pandemic, the significant increase in food delivery transactions indicates that online food purchases have become more common. The convenience of searching for food on the Internet has brought more opportunities for the catering industry, and at the same time, it has brought more fierce competition. Therefore, for the catering industry, it is essential to find the food charm that attracts customers and present it in pictures on the Internet for food marketing through the Internet.

Consumers perceive and cognize the product while they buy, prepare, and consume it. Different consumer groups and different restaurant types have different demands for food design. Therefore, to segment the market, the food providers should consider the food design and the resulting visual appeal. For example, Figure 1 illustrates three different styles of mango ice photos that convey three different Kansei perceptions. Vision plays a vital role in the human experience of the five senses.
Research surveys show that when the human body uses five senses, the depth of perception is "vision (37\%)", "olfaction (23\%)", "hearing (20\%)", " gustation (15\%)", and finally "tactile perception (5\%)", where visual effects rank first. Ho and Hou indicated that the first impression that people have toward an object is visual (Ho \& Hou, 2015). Tractinsky and Hassenzahl showed that the impressions of aesthetics are rapid, lasting, and consequential (Tractinsky \& Hassenzahl, 2005).

Perception and cognition are based on sensorial observations of the individual and product characteristics. Product characteristics like package, appearance, taste, and smell influence consumers' perception and cognition. There is evidence that food preference constitutes one of the strongest single predictors of food choices and food acceptance (Meiselman, 1996; Grunert et al., 1995). Therefore, making the product development process more consumer-oriented is critical for food producers. Factors that trigger the motivation of food consumption include appearance, aroma, and taste. When developing or preparing dishes, the chef is very particular about these three. However, limited by the technology and functions of the existing e-commerce platform, consumers cannot feel the product behind the screen through the smell and taste. Choosing food from the pictures 
on the website has become an important process of online food consumption. Therefore, the visual appeal of food is the key to trigger consumption motivation. However, consumers' perception of visual charm depends on many various complex psychological and environmental factors (Baker et al., 1992; Saad \& Metawie, 2015). Finding out the factors that associate the psychological feelings and images of consumers with a new product is a key issue for impressing consumers (Nagamachi, 1995, 2002).

Since its introduction in the 1980s, Kansei Engineering has been valued and adopted in various fields to translate for costumer's psychological feeling into design specifications. (Nagelkerke, 1991; Nagamachi, 2008; Djatna \& Kurniati, 2015; Jiao et al., 2006; Nagamachi, 2002, 1995). Miryoku engineering was incorporated as a part of Kansei Engineering by the Japanese Society of Kansei Engineering, founded in 1998 (Ujigawa, 2000). It was initiated by Masato Ujigawa in 1991, which aims at "Technology and knowledge to create attractive products and spaces". Miryoku is the attraction that can induce consumption motivation. It makes consumers' subjective preferences and consumer value directly and closely related (Zhang \& Li, 2019). Evaluation Grid Method (EGM) was proposed by Sanui Junichiro (Sanui, 1996), and has become one of the most effective way to capture and classify the psychological needs of consumers in recent years (Chang \& Chen, 2017). It summarizes individual characters of objects after discussing the similarity and differences among them through personal interviews and pairing comparison. In the step of pairing comparisons, ask people to respond to what they like or dislike. Second, based on their answers, supplementary questions are used to clarify the meaning or conditions. In this step, the user's perception of products in the ambiguous information can be logically organized and compiled in hierarchical structures (Zhang \& Li, 2019).

"Food Kansei Model" is a food-related Kansei engineering method (Sagara, 2001; Ikeda et al., 2004; Ito et al., 1994), which aims to establish the relationship between food characteristics and perceived quality. According to the Food Kansei model, the characteristics of food are divided into intrinsic and extrinsic attributes. The intrinsic attributes are consumers' perceptions of food's physical and chemical characteristics in terms of taste, smell, and touch. These perceptions will affect consumers' preference for food. The extrinsic attributes are Consumers' cognition of food characteristics in terms of vision and hearing will affect consumers' attitudes towards food, as shown in Figure 2. The consumer experience and attitudes caused by preferences will create expectations for products, which affects consumers' preferences for food.

Limited by the functions of the current Internet platform, the visual characteristics of food can affect the purchase intention of consumers behind the screen more than other characteristics such as smell and taste. According to the food Kansei model, the visual characteristics of food images are extrinsic attributes, which will affect consumers' cognition, attitudes, expectations of food, and purchase intentions. The purpose of this study is to explore the relationship between the visual characteristics of food images and consumer cognition based on the theory of food Kansei model. Take Taiwanese mango ice photos provided by stores on the Internet platforms as an example to explore the

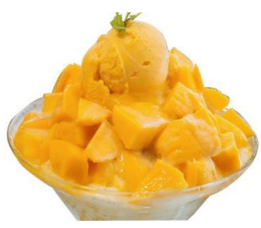

(a) abundant

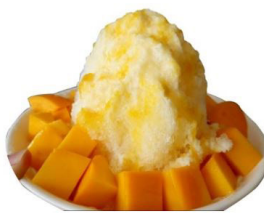

(b) cool and fresh

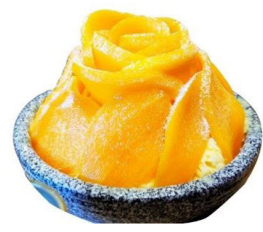

(c) designed appearance

Figure 1. Different designs of mango ice create different visual attractiveness.

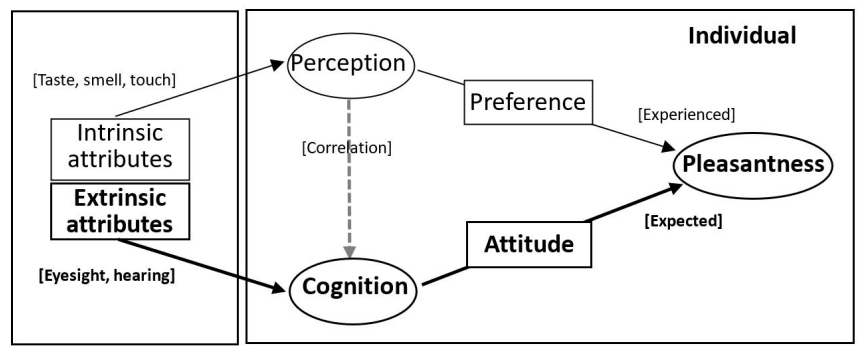

Figure 2. Food Kansei model. Source: own elaboration based on Ito (Ito et al., 1994).

impact of the photo features on consumers' food consumption choices of the food.

Many studies have explored the influence of consumer expectations on food through graphic packaging characteristics (such as labels, colors) and structural characteristics (such as shapes, material types) (Ampuero \& Vila, 2006). For example, Deliza et al. (2003) discussed the influence of the background color of juice packaging on consumers' expected mentality of juice freshness. Puyares et al. (2010) found that the expected organoleptic properties of wine can also be adjusted by the shape and color of the bottle. Piqueras-Fiszman \& Spence (2011) explored the relationship between the color of potato chip packaging and consumer expectations of flavor. Meillon et al. (2010) suggested that consumer liking for wine was modulated by labeling information.

The researches mentioned above show that the shape and color of the outer packaging of different types of prepared foods impact consumers' expectations of mentality (Labbe et al., 2013). Even though the effects of visual features of packaging on expected food characteristics have been extensively studied in the past decade, research on the influence of visual characteristics of meal images on consumers is relatively rare. Recently, due to the impact of the new crown pneumonia epidemic, ordering delivery meals through online platforms has become a safer option than dining at restaurants. Consumers' demand for buying food through online platforms has therefore increased. Compared with pictures of packaged foods, food images used for online catering sales are more complex and diverse.

This study takes Taiwan mango ice as an example, based on the food Kansei model, using the evaluation grid method and quantitative multiple regression to discover specific characteristics 
(attributes) of catering images and explore the relationship between these attributes and the consumer's expected cognition factors.

\section{Materials and methods}

In this study, taking Taiwan mango ice as an example, combining qualitative and quantitative methods, discovered and analyzed food photos' attractiveness. In the qualitative part of this study, EGM is used to extract the attractiveness of mango ice photos through in-depth interviews with participants. In quantitative research, we developed the questionnaire using the attractiveness factors found in qualitative research and built the mathematical models using QTT1 technology. Mathematical models are used to express the relationship and importance of design elements and Kansei feelings. The entire research process is as follows:

\subsection{Sample selection}

Since Miryoku engineering is based on the analysis of the user's psychological perception to capture personal cognitive concepts of the stimuli and organize them, the stimulus of the experiment should be relatively concrete and contains as many product categories as possible. The sample images of mango ice are collected based on recommendations from 73 food intelligence bloggers who have entered the top 100 in PIXNET's "community influence ranking." PIXNET is one of the most visited self-media platforms. PIXNET has become the largest blogging platform in Taiwan, mainly providing online community services such as blogs, online photo albums, and message boards (Chen, 2019; Wang, 2019). According to the "Top Sites in Taiwan" traffic ranking shown on the Alexa website in April 2020, PIXNET ranks 4th in Taiwan, and the traffic is second only to Google, Youtube, and Ettoday.

Those bloggers recommended sixty-four mango ice shops. Mango ice photos provided by 64 ice shops on websites, books, and magazines are collected and made into $640 \times 480$ pixels in color with clear design details sample cards. After that, these photos were screened by focus group members consisted of five graduate school students (three students with food and beverage background, and two students with design background) with more than 3 years of related working experience. They screened the sample images and remove less representative samples with duplicate characteristics. Finally, 40 representative experimental samples were obtained with diverse styles on the basis of ice, mango, minor ingredients, container, dressing, and integral of mango ice.

\subsection{Evaluation Grid Method (EGM) interview}

In the EGM interview experiment, since data collection is conducted in depth interviews and takes more time, it is not suitable for large-scale investigations (Reynolds \& Gutman, 1984; Park et al., 1986). In this study, 8 experts who have more than 3 years of catering-related work or mango ice highly involved experience were invited for interviews at different times. These interviewees addressed their preferences toward 40 mango ice sample cards. The detail information of interviewees is presented in Table 1.

In the interview, the interviewees' personal cognition about the stimulus samples and the appealing features of products perceived are needed to be recorded and organized to conduct the evaluation grid method. The respondent must select a sample he prefers from the pair-wise comparison samples, and answer his/her reasons for preferring that sample. The reasons for preference including the "original evaluation items" (OEI), "abstract evaluation items" (AEI), and 'concrete evaluation items'(CEI) should be recorded. The original evaluation items are the preference reasons come out firstly in interviewee's own word. The abstract evaluation items furthermore are descriptions that interviewee gave when they are asked for more abstract meanings and emotions behind the first response. And then, the concrete evaluation items are the reasons given by interviewees when they are asked for more concrete formative conditions and features of the reasons.

Through in-depth interviews, record the original, abstract, and concrete evaluation items for the attractiveness of mango ice images obtained from 8 experts after pairwise comparison of samples. Then, the KJ method (Ohiwa et al., 1997) was adopted to collects experts' different opinions and uses all the relationships to sort them out. (Hanington \& Martin, 2012) Firstly, the opinions of experts were externalized and atomized into cards. Secondly, the cards were categorized, clustered, and named. Then, we considered the mentioned frequency of opinions and integrated all evaluation items obtained into a three-tier hierarchy diagram as shown in Figure 3.

The abstract reason shown on the left hand side of the diagram includes three items, they are "abundant ", "cool and fresh", and "designed appearance", which represent the psychological perception and feeling brought by the sample photos of mango ice, which will affect consumers' attitudes and expectations. On the right hand side of the diagram, 16 concrete evaluation items of mango ice image were derived from the original reason. All

Table 1. Information of focus group members.

\begin{tabular}{ccccc}
\hline Interviewee number & Gender & Age & related working experience & seniority \\
\hline 1 & Male & 32 & mango fruit farmer, mango product producer & 6 \\
2 & Female & 40 & Food blogger, Chef & 5 \\
3 & Female & 35 & Ice dessert shop owner & 7 \\
4 & Male & 31 & Vegetarian restaurant chef & 8 \\
5 & Female & 28 & Bakery chef & 5 \\
6 & Male & 50 & Catering R\&D staff & 23 \\
7 & Male & 32 & Catering R\&D staff & 6 \\
8 & Female & 26 & Dessert Chef & 4 \\
\hline
\end{tabular}


items are connected with straight lines to indicate the hierarchical relationships.

\subsection{Questionnaire designed for Kansei evaluation}

A questionnaire of Kansai evaluation is developed for conducting multiple linear regression to determine design elements that influenced users' feelings. The first part of the questionnaire is to request the primary personal data of the respondents, and the second part is for collecting the participant's psychological perceptive score for each mango ice sample image. In this part, participants will be shown 40 mango ice sample images (640x480 pixels) and asked to rate the degree of approval for three AEI (abundant, cool and fresh, and designed appearance), which represents interviewees' Kansei cognition about each sample image. Each Kansei cognition is scored using a five-point Likert scale, where " 1 = highly disagree", " 2 = disagree", " $3=$ neutral", " $4=$ agree" and " $5=$ highly agree". The Kansei scores collected from this part will be used as the dependent variables in the subsequent quantitative type I analysis. Table 2 shows the format of the Kansai evaluation questions.

\subsection{Statistical analysis - Quantification Theory Type (QTT)}

The Kansei evaluation surveys were made available by various social media and professional contacts of the authors. Forty ice mango photo samples are evaluated for three abstract evaluation items (Kansei words). A total of 234 responses were obtained. Each response has evaluated at least 20 samples among the posted 40 samples, and at least 70 respondents evaluate each sample. The majority of respondents were women (147 people,

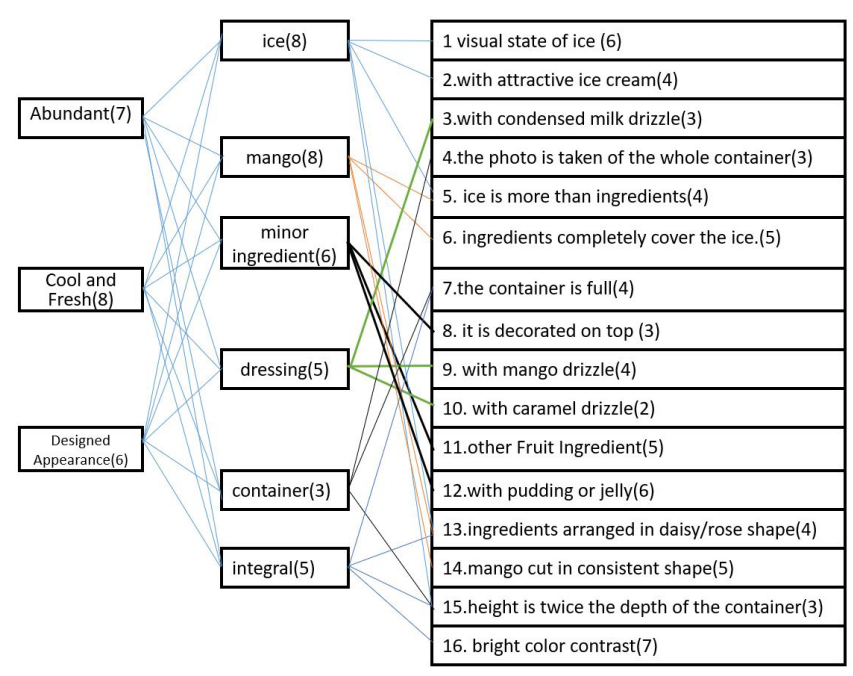

Figure 3. The EGM hierarchical diagram of mango ice image preference.
$63 \%)$, compared to 54 men (33.5\%). The most respondents (98 people, $42 \%$ ) fell into the age range ' $20 \sim 29$ years', followed by '0 20 years' (69 people, 18\%). After obtaining the questionnaire results, calculate the individual average score of each sample photo in the three abstract evaluation items and used them as the dependent variables in QTT1 to discover the relationship between the AEIs and CEIs.

The categories of each concrete evaluation item are determined and marked by the members of the focus group. The decision criterion is based on the relative majority. Each experimental sample only responds to one category in each design element. Therefore, the dummy variable $\mathrm{x}_{i j \mathrm{~s}}$ of the design element in the multiple regression analysis must meet the following conditions (Equation 1) (Komozava and Hayashi, 1976):

$x_{i j s}=\left\{\begin{array}{l}1, \\ 0,\end{array}\right.$

when sample s corresponds to category $\mathrm{j}$ of design element $\mathrm{i}$

where $x_{i j s}$ satisfies $\sum_{j=1}^{C_{i}} x_{i j s}=1, \forall$ i and $\mathrm{s}$,

Table 3 shows the categories of each concrete evaluation item which were used as dummy variables and the scores of the three abstract evaluation items for each sample. QTT1 analysis will further then be used to examine the relationship between the 16 concrete evaluation items and 3 abstract evaluation items.

\subsection{Quantitative theory type 1}

Quantitative theory type 1 is a multiple regression method for processing data of nominal scaled independent variables (Komozava \& Hayashi, 1976; Lin et al., 2012; Djatna \& Kurniati, 2015). It is used to synthesize the result of evaluation. The Kansei relational model of this study is defined as Equation 2:

$\hat{y}_{s}^{k}=\sum_{i=1}^{E} \sum_{j=1}^{C_{i}} \beta_{i j} x_{i j s}+\varepsilon$

$\hat{y}_{s}^{k}$ :the predicted value of the criterion variable for the sth product sample on the kth image word

$i$ :the index of design element

E:the number of design element

$j$ :the index of category

$C i$ the number of category of the ith design element $\varepsilon$ : a stochastic variable whose expectation value $\mathrm{E}(\varepsilon)=0$

$\beta_{i j}$ : the category score of the $\mathrm{jth}$ style within the ith design element

Table 2. Question format of the Kansei Questionnaire.

Score the following Kansei cognitions about the mango ice image on the left hand side $1=$ highly disagree, $2=$ disagree, $3=$ neutral, $4=$ agree and $5=$ highly agree

\begin{tabular}{|c|c|c|c|c|c|}
\hline (A) Abundant, profusion, and satiety & $1 \square$ & $2 \square$ & $3 \square$ & $4 \square$ & $5 \square$ \\
\hline (B) Designed appearance/pleasing to the eye & $1 \square$ & $2 \square$ & $3 \square$ & 4 口 & $5 \square$ \\
\hline (C) Cool and fresh & $1 \square$ & $2 \square$ & $3 \square$ & $4 \square$ & $5 \square$ \\
\hline
\end{tabular}


Table 3. The category for concrete evaluation items and the average for abstract evaluation items.

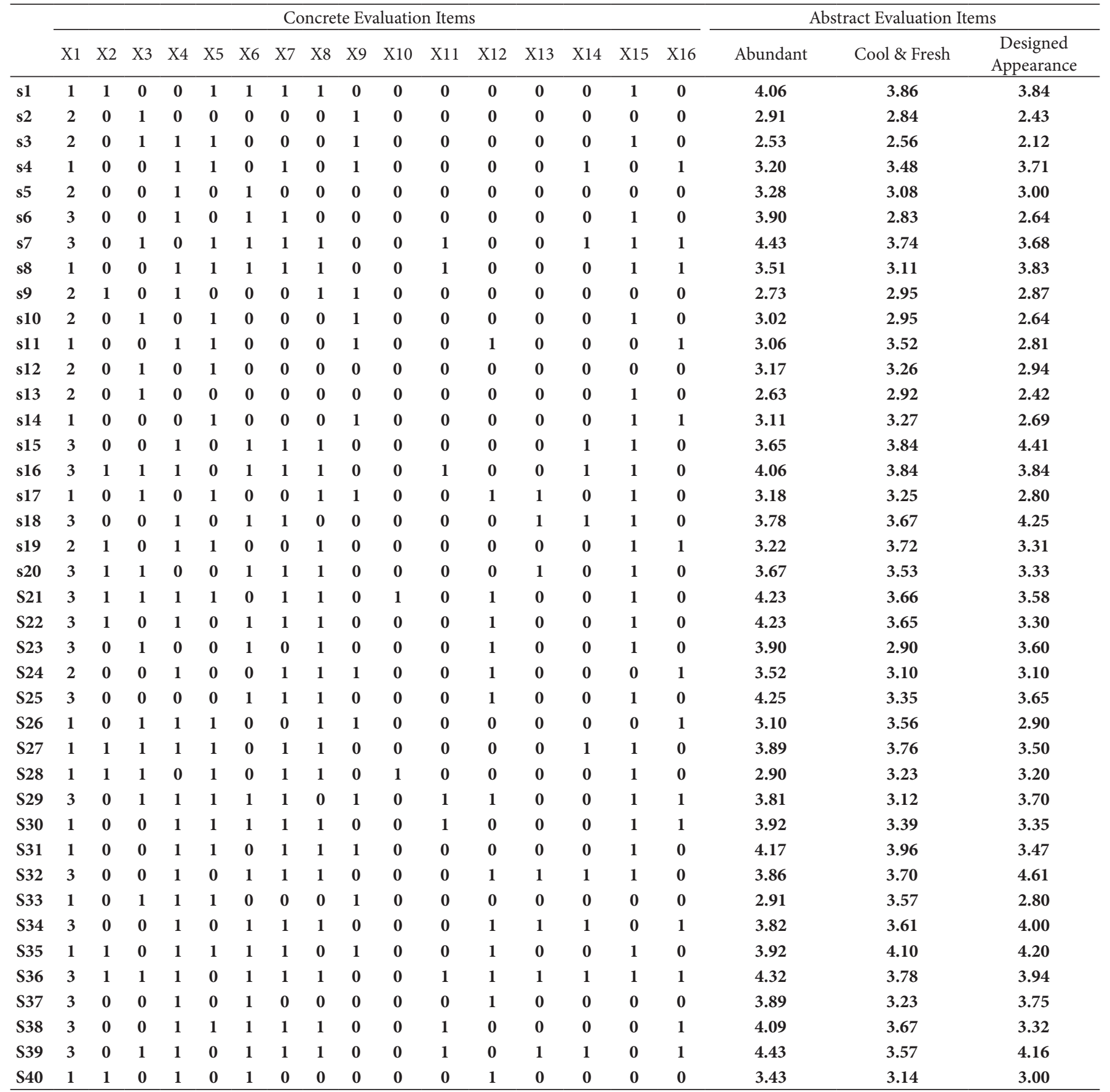

$\mathrm{X}=$ categories of each concrete evaluation item which were used as dummy variables; $\mathrm{S}=$ the scores of the three abstract evaluation items for each sample.

$x_{i j s}$; the dummy variable representing the jth style within the ith design element using the sth experimental sample

In estimating the coefficients of dummy variables, the least square method is used to minimize the squared prediction difference between actual observed value $y_{s}^{k}$ and predicted value $\hat{y}_{s}^{k}$. Then, standardization for the regression coefficients is performed. The formula with standardized coefficient and constant is redefined as Equation 3
$\hat{y}_{s}^{k}=\sum_{i=1}^{E} \sum_{j=1}^{C_{i}} \beta_{i j}^{*} x_{i j s}+\bar{y}_{s}^{k}$

where $\beta_{i j}^{*}$ denotes the standardized coefficient of explanatory variables and $\bar{y}_{s}^{k}$ denotes the standardized constant. They are defined as Equation 4 and 5

$\beta_{i j}^{*}=\beta_{i j}-\frac{1}{n} \sum_{j=1}^{C_{i}} \beta_{i j} x_{i j s}$ 
$\bar{y}_{s}^{k}=\frac{1}{n} \sum_{s=1}^{n} y_{s}^{k}$

where $n$ denotes the number of experimental samples.

To determine the relational degree of each criterion variable and the explanatory variables, multiple correlation coefficient $\mathrm{R}$ is calculated, and the coefficient of multiple determination can be obtained by $\mathrm{R}^{2}$ that is considered as the contribution degree to goodness of fit of the regression model (Nagelkerke, 1991). In Kansei Engineering, an $R^{2}$ greater than 0.5 is generally considered acceptable (Nishino, 2001). The partial correlation coefficients (PCC) of design elements and the statistical range of categorical variables are also determined. The PCC indicates the effect of a design element (concrete evaluation item) on a specific product image (abstract evaluation item) and the statistical range of categorical variables indicate the contribution degree of a design element to the prediction model with respect to a given product image. In order to confirm which independent variables in the regression have a significant influence on the dependent variable, the $t$ value of each CEI of each regression model is calculated to show its significance.

\section{Results and discussion}

The result of conducting QTT1 via statistical software and programming tools was represented in Table 4. The coefficients of multiple determination $\left(\mathrm{R}^{2}\right)$ for each model are 0.827 (abundant), 0.705 (cool and fresh), and 0.808 (designed appearance), respectively. These results show that the overall fits of these QTT1 function models are good. Table 4 lists the category scores (CS), the statistical range, and the partial correlation coefficients (PCC) of 16 concrete evaluation items. The category score (CS) is the standardized regression coefficient calculated according to Equation 4. Because CEI with a higher PCC value has a higher correlation with the dependent variable, it contributes to the prediction model. In Table 4, items with a PCC value close to or greater than 0.5 , which have significant effects on predicting the degree of AEI, were highlighted. The CEIs affecting the three AEIs are described below:

\section{Weighting the appeal of the 'abundant' factor}

Through the EGM diagram and results of QTT1, the primary factors with a significant influence on users' perception of "abundant" were "visual state of ice" $(\mathrm{PCC}=0.562)$, "the container is full" (PCC $=0.512)$, "with caramel drizzle" $(\mathrm{PCC}=0.456)$, and "with pudding or jelly" (PCC $=0.503)$. The category "ice is not visible" within the CEI "visual state of ice" produced the greatest positive influence $(C S=0.323)$, and the category "lacked" within the CEI "with caramel drizzle" produced the greatest negative influence $(\mathrm{CS}=-0.779)$.

\section{Weighting the appeal of the 'cool and fresh' factor}

Through the EGM diagram and results of QTT1, the primary factors with a significant influence on users' perception of "cool and fresh" were "ice is more than ingredients" (PCC $=0.567)$, "with attractive ice cream" (PCC $=0.504)$, and "visual state of ice". (PCC $=0.393$ ) The category "fulfilled" within the CEI "with attractive ice cream" produced the greatest positive influence $(C S=0.221)$, and the category "ice is visible and melted' within the CEI "visual state of ice" produced the greatest negative influence $(\mathrm{CS}=-0.284)$.

\section{Weighting the appeal of the "designed appearance" factor}

Through the EGM diagram and results of QTT1, the primary factors with a significant influence on users' perception of "designed appearance" were "mango cut in consistent shape" $(\mathrm{PCC}=0.642)$, and "ingredients completely cover the ice" (PCC $=0.449)$. The category 'fulfilled' within the CEI "mango cut in consistent shape" produced the greatest positive influence $(\mathrm{CS}=0.323)$, and the category "lacked" within the CEI "ingredients completely cover the ice" produced the greatest negative influence $(C S=-0.416)$.

Table 5 shows that ranking of top 25\% and bottom 25\% example photos for 3 abstract evaluations (abundant, cool and fresh, and designed appearance). In the top 25\% of the "abundant", the predicted samples are $70 \%$ correct for the observed samples. On the other hand, in the ranking of the bottom 25\%, the predicted samples have an accuracy rate of $80 \%$ for the observed samples and make the average prediction result of "abundant" $75 \%$ correct. In terms of "cool and fresh," among the top 25\%, the predicted sample is $80 \%$ correct for the observed sample. On the other hand, in the bottom $25 \%$ ranking part, the accuracy rate of the predicted sample to the observed sample is also $80 \%$. As for "designed appearance", among the top 25\%, the predicted sample is $90 \%$ correct for the observed sample. On the other hand, in the bottom $25 \%$ ranking part, the accuracy rate of the predicted sample to the observed sample is also $70 \%$.

In actual applications, the top and bottom rankings are more helpful to food designers than the middle rankings. They provide clues to food designers for learning how to have design elements that consumers love and how to avoid elements that consumers hate. In addition, since the coefficient of determination $\left(R^{2}\right)$ is a statistical measurement that examines how strong the linear relationship is between the dependent and independent variables. The accuracy obtained in this experiment can also confirm the credibility of $\mathrm{R}^{2}$ of the regression model obtained in this study.

\section{Conclusions}

It is of great significance to design food photos for advertising in consideration of user perception and cognition. This study evaluated the attractive design elements of mango ice photos currently on the market based on advertising photos provided by mango ice shops highly acclaimed on the Internet. A focus group that includes members with specific experience in food production, design, and marketing and who love mango ice was formed for EGM experiments to retrieve the abstract and concrete evaluation items. After retrieving the evaluation items, QTT1 for quantitative analysis was adopted. Then, we synthesized customers' emotional cognition with concrete design elements about the mango ice photo. The applications of this study have important reference value for evaluating food design elements and market segmentation of consumer groups. This research result proves the feasibility of using Kansei engineering to 
Table 4. The result of conducting QTT1 via statistical software and programming tools.

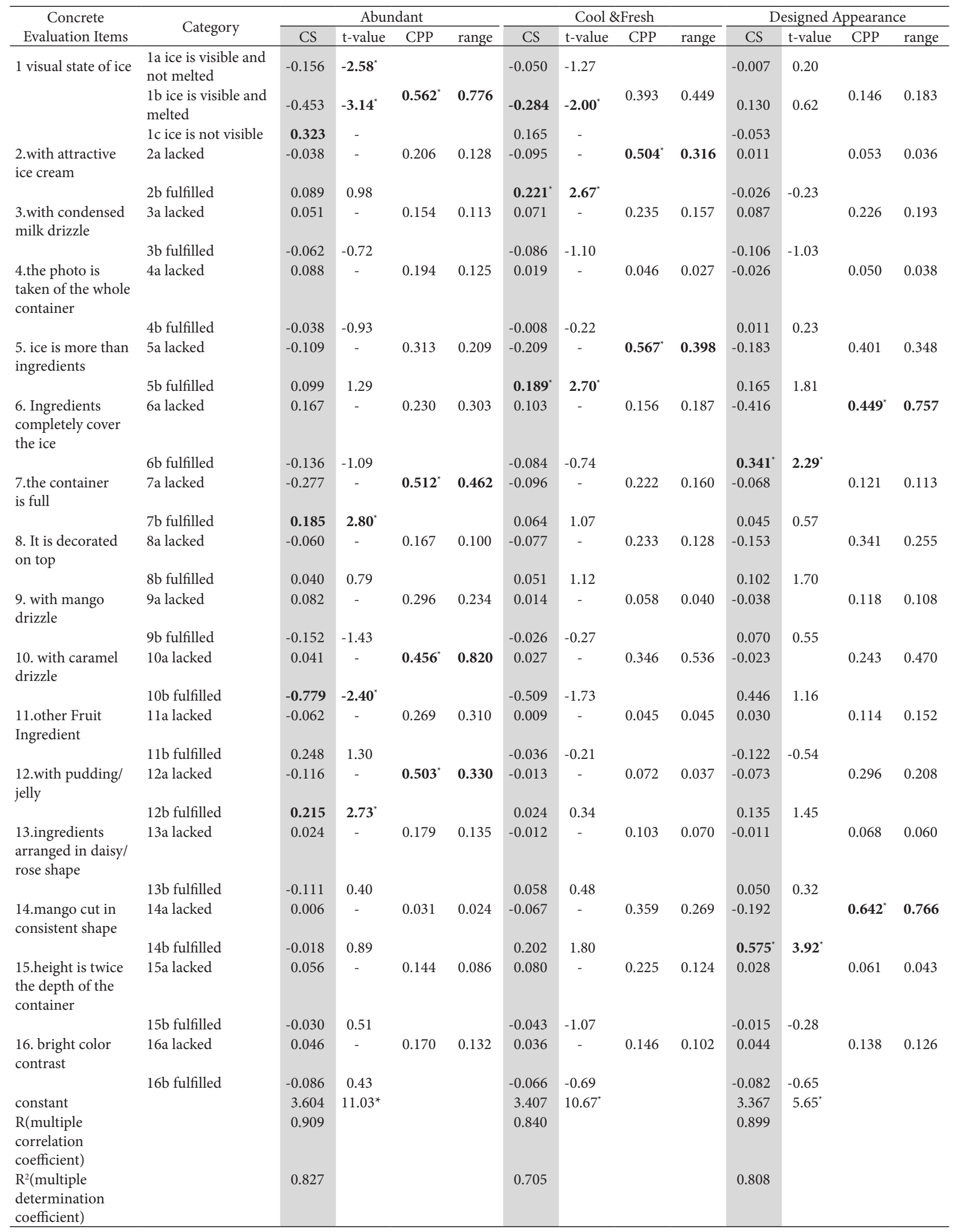


Table 5. Accuracy of top 25\% and bottom 25\% ranking samples for 3 AEIs.

\begin{tabular}{|c|c|c|c|c|c|c|c|c|c|c|c|c|}
\hline \multirow{3}{*}{$\begin{array}{l}\text { Factors } \\
\text { ranking }\end{array}$} & \multicolumn{4}{|c|}{ Abundant } & \multicolumn{4}{|c|}{ Cool \&Fresh } & \multicolumn{4}{|c|}{ Designed Appearance } \\
\hline & \multicolumn{2}{|c|}{ Top 25\% } & \multicolumn{2}{|c|}{ bottom $25 \%$} & \multicolumn{2}{|c|}{ Top 25\% } & \multicolumn{2}{|c|}{ bottom $25 \%$} & \multicolumn{2}{|l|}{ Top 25\% } & \multicolumn{2}{|c|}{ bottom $25 \%$} \\
\hline & Observed & Predicted & Observed & Predicted & Observed & Predicted & Observed & Predicted & Observed & Predicted & Observed & Predicted \\
\hline 1 & s7 & s38 & s3 & s3 & s35 & s27 & s3 & $\mathrm{s} 13$ & s32 & s32 & s3 & s13 \\
\hline 2 & s39 & s22 & s13 & s2 & s31 & s1 & s6 & $\mathrm{s} 2$ & s15 & s34 & s13 & $\mathrm{s} 2$ \\
\hline 3 & s36 & s25 & s9 & s10 & s1 & s4 & s2 & s3 & s18 & s15 & $\mathrm{s} 2$ & s14 \\
\hline 4 & s25 & s7 & $\mathrm{s} 28$ & s13 & s15 & s34 & s23 & s10 & s35 & s7 & s10 & s12 \\
\hline 5 & $s 21$ & s36 & s33 & s9 & s16 & s7 & s13 & s23 & s39 & s18 & s6 & s33 \\
\hline 6 & s22 & s16 & $\mathrm{s} 2$ & $s 26$ & s36 & s36 & s10 & s24 & s34 & s36 & s14 & s10 \\
\hline 7 & s31 & s29 & s10 & s33 & s27 & s16 & s9 & s5 & s36 & s35 & s33 & s3 \\
\hline 8 & s38 & s32 & $s 26$ & s14 & s7 & s32 & s5 & s12 & s1 & s39 & s17 & s26 \\
\hline 9 & s1 & s34 & s12 & s19 & s19 & s38 & s24 & s6 & s16 & s16 & s11 & s9 \\
\hline 10 & s16 & s21 & s17 & s12 & s32 & s35 & s8 & s37 & s8 & s1 & s9 & s19 \\
\hline accuracy & \multicolumn{2}{|c|}{$70 \%$} & \multicolumn{2}{|c|}{$80 \%$} & \multicolumn{2}{|c|}{$70 \%$} & \multicolumn{2}{|c|}{$80 \%$} & \multicolumn{2}{|c|}{$90 \%$} & \multicolumn{2}{|c|}{$70 \%$} \\
\hline
\end{tabular}

explore the charm of food design, and has reference value for future related research.

\section{Acknowledgements}

The authors thank the anonymous reviewers for their constructive comments. This work was supported by the Ministry of Science and Technology MOST 108-2637-E-328-001, Taiwan.

\section{References}

Ampuero, O., \& Vila, N. (2006). Consumer perceptions of product packaging. Journal of Consumer Marketing, 23(2), 100-112. http:// dx.doi.org/10.1108/07363760610655032.

Baker, J., Levy, M., \& Grewal, D. (1992). An experimental approach to making retail store environmental decisions. Journal of Retailing, 68(4), 445.

Chang, H. C., \& Chen, H. Y. (2017). Exploration of action figure appeals using evaluation grid method and quantification theory type I. Eurasia Journal of Mathematics, Science and Technology Education, 13(5), 1445-1459.

Chen, L. C. (2019). Based on the document-link and time-clue relationships between blog posts to improve the performance of Google blog search. International Journal on Semantic Web and Information Systems, 15(1), 52-75. http://dx.doi.org/10.4018/ IJSWIS.2019010103.

Nagamachi, M. (2008). Perspectives and the new trend of Kansei/ affective engineering. The TQM Journal, 20(40), 290-298.

Deliza, R., Macfie, H. A. L., \& Hedderley, D. (2003). Use of computergenerated images and conjoint analysis to investigate sensory expectations. Journal of Sensory Studies, 18(6), 465-486. http:// dx.doi.org/10.1111/j.1745-459X.2003.tb00401.x.

Djatna, T., \& Kurniati, W. D. (2015). A system analysis and design for packaging design of powder shaped fresheners based on Kansei engineering. Procedia Manufacturing, 4, 115-123. http://dx.doi. org/10.1016/j.promfg.2015.11.021.

Grunert, K. G., Larsen, H. H., Madsen, T. K., \& Baadsgaard, A. (1995). Market orientation in food and agriculture. Boston: Springer Science \& Business Media.

Hanington, B., \& Martin, B. (2012). Universal methods of design: 100 ways to research complex problems. Beverly: Rockport Publishers.
Ho, C. H., \& Hou, K. C. (2015). Exploring the attractive factors of app icons. Transactions on Internet and Information Systems, 9(6), 2251-2270.

Ikeda, G., Nagai, H., \& Sagara, Y. (2004). Development of food kansei model and its application for designing tastes and flavors of green tea beverage. Food Science and Technology Research, 10(4), 396-404. http://dx.doi.org/10.3136/fstr.10.396.

Ito, M., Umemoto, M., Yamadori, A., Ono, T., Tokosumi, A., \& Ikeda, K. (1994). Emotion (vol. 6, Cognitive Science). Tokyo: Iwanana Shoten Publishing (in Japanese).

Jiao, J. R., Zhang, Y., \& Helander, M. (2006). A Kansei mining system for affective design. Expert Systems with Applications, 30(4), 658673. http://dx.doi.org/10.1016/j.eswa.2005.07.020.

Komozava, T., \& Hayashi, C. (1976). A statistical method for quantifying of categorical data and its application to medical science. Amsterdam: North Holland publishing company.

Labbe, D., Pineau, N., \& Martin, N. (2013). Food expected naturalness: impact of visual, tactile and auditory packaging material properties and role of perceptual interactions. Food Quality and Preference, 27(2), 170-178. http://dx.doi.org/10.1016/j.foodqual.2012.06.009.

Lin, Y. C., Yeh, C. H., Wang, C. C., \& Wei, C. C. (2012). Is the linear modeling technique good enough for optimal form design? A comparison of quantitative analysis models. The Scientific World Journal, 2012, 689842. http://dx.doi.org/10.1100/2012/689842. PMid:23258961.

Meillon, S., Viala, D., Medel, M., Urbano, C., Guillot, G., \& Schlich, P. (2010). Impact of partial alcohol reduction in Syrah wine on perceived complexity and temporality of sensations and link with preference. Food Quality and Preference, 21(7), 732-740. http:// dx.doi.org/10.1016/j.foodqual.2010.06.005.

Meiselman, H. L. (1996). The contextual basis for food acceptance, food choice and food intake: the food, the situation and the individual. In H. L. Meiselman (Ed.), Food choice, acceptance and consumption (pp. 239-263). Boston: Springer.

Nagamachi, M. (2002). Kansei engineering as a powerful consumeroriented technology for product development. Applied Ergonomics, 33(3), 289-294. http://dx.doi.org/10.1016/S0003-6870(02)00019-4. PMid:12164511.

Nagamachi, M. (1995). Kansei engineering: a new ergonomic consumeroriented technology for product development. International Journal 
of Industrial Ergonomics, 15(1), 3-11. http://dx.doi.org/10.1016/01698141(94)00052-5.

Nagelkerke, N. J. D. (1991). A note on a general definition of the coefficient of determination. Biometrika, 78(3), 691-692. http:// dx.doi.org/10.1093/biomet/78.3.691.

Nishino, T. (2001). Exercises on Kansei Engineering. Hiroshima: Hiroshima International University.

Ohiwa, H., Takeda, N., Kawai, K., \& Shiomi, A. (1997). KJ editor: a card-handling tool for creative work support. Knowledge-Based Systems, 10(1), 43-50.

Park, C. W., Jaworski, B. J., \& MacInnis, D. J. (1986). Strategic brand concept-image management. Journal of Marketing, 50(4), 135-145. http://dx.doi.org/10.1177/002224298605000401.

Piqueras-Fiszman, B., \& Spence, C. (2011). Crossmodal correspondences in product packaging. Assessing color-flavor correspondences for potato chips (crisps). Appetite, 57(3), 753-757. http://dx.doi. org/10.1016/j.appet.2011.07.012. PMid:21824502.

Puyares, V., Ares, G., \& Carrau, F. (2010). Searching a specific bottle for Tannat wine using a check-all-that apply question and conjoint analysis. Food Quality and Preference, 21(7), 684-691. http://dx.doi. org/10.1016/j.foodqual.2010.05.008.

Reynolds, T. J., \& Gutman, J. (1984). Advertising is image management. Journal of Advertising Research, 24(1), 27-37.
Saad, M., \& Metawie, M. (2015). Store environment, personality factors and impulse buying behavior in Egypt: the mediating roles of shop enjoyment and impulse buying tendencies. Journal of Business and Management Sciences, 3(2), 69-77.

Sagara, Y. (2001). “Kansei” engineering for investigating food preference. The Japanese Journal of Taste and Smell Research, 8, 153-159.

Sanui, J. (1996, August 18-21). Visualization of users' requirements: introduction of the Evaluation Grid Method. In H. Timmermans (Ed.), Proceedings of the 3rd Design \& Decision Support Systems in Architecture \& Urban Planning Conference (pp. 365-374). Spa, Belgium: Computer Aided Architectural Design.

Tractinsky, N., \& Hassenzahl, M. (2005). Arguing for aesthetics in human-computer interaction. I-com, 4(3), 66-68. http://dx.doi. org/10.1524/icom.2005.4.3.66.

Ujigawa, M. (2000). The evolution of preference-based design. Research and development Institute, 46, 1-10.

Wang, R. (2019, December 5). Big data alchemy from 800 million tribal articles: PIXNET. $i$ Thome. Retrieved from https://www.ithome.com. tw/people/134613

Zhang, B. Y., \& Li, J. (2019). Design for environmental protection: measuring the appeal factors of green product for consumers. Ekoloji Dergisi, 28(107), 1699-1707. 